\title{
The acquisition of functional categories in early French second language grammars: the use of finite and non-finite verbs in negative contexts
}

\section{Sarah Rule University of Southampton and Emma Marsden University of York}

Received July 2003; revised December 2004; accepted March 2005

This cross-sectional study of first language (L1) English adolescents learning French as a second language (L2) uses their development of negatives in relation to finite and non-finite verbs to investigate the status and nature of functional categories in these learners' emerging grammars. Analysing oral data from elicited production tasks from instructed learners, it provides evidence for a lack of functional categories in the Initial State and the earliest L2 grammars (Vainikka and Young-Scholten, 1996; Hawkins, 2001). However, the results from the study also indicate that the functional category I (or T) then emerges reasonably rapidly. The pattern of development of negation and finite and non-finite verbs in these learners' grammars also suggests that feature values are in place for the functional categories once they are projected, as learners consistently raise the verb. The learners do use root infinitives but the properties of these root infinitives differ to those found in L1 acquisition (Pierce, 1992; Wexler, 1994; 1998), thus supporting Wexler's maturational account of Optional Infinitives in L1 acquisition. Additionally, the rare occurrence of raised non-finite verbs would indicate that there is a problem with the realization of surface morphology in accordance with the Missing Surface Inflection Hypothesis of Prévost and White (2000a) rather than an impairment in the grammar (Meisel, 1997; Hawkins, 2000).

Address for correspondence: Sarah Rule, Department of Modern Languages, University of Southampton, Highfield, Southampton, SO51 7TQ, UK; email: s.j.rule@ soton.ac.uk 


\section{Introduction}

For those researchers who adopt a generative approach to second language acquisition, the debate on the acquisition of functional categories in early second language (L2) grammars continues. The debate centres on the presence or absence of functional categories in the initial state and subsequent emerging grammars, and what properties they may have once they are projected. For some researchers, functional categories are initially absent in these early stages and learners only project lexical categories: learners will only project a VP initially. In their Minimal Trees hypothesis, Vainikka and Young-Scholten (1996) suggest that functional categories are gradually triggered by positive evidence of overt syntactic distribution or overt morphology in the input. For others, functional categories and their projections are available to both child and adult L2 learners from the outset, either directly from Universal Grammar (Epstein et al., 1996; Grondin and White, 1996) or from the first language (L1) grammar (Schwartz and Sprouse, 1996; Herschensohn, 2001; Haznedar, 2003).

Even once they are projected, an additional polemic surrounds the exact nature of functional categories in L2 grammars. This concerns the explanations provided for apparent optionality in L2 learners' grammars, evidenced in the switching between finite and non-finite verbs in their productions in obligatory finite contexts. Recently this polemic has centred on the relationship between knowledge of inflectional morphology and knowledge of related functional categories and their feature values. On the one hand, proponents of the Missing Surface Inflection Hypothesis (MSIH) (Haznedar and Schwartz, 1997; Prévost and White, 2000a; 2000b; Herschensohn, 2001; Ionin and Wexler, 2002; Haznedar, 2003) claim that L2 learners have unconscious knowledge of the functional projections and feature values underlying tense and agreement. In this view, optionality in the use of inflectional morphology is a problem with the realization of surface morphology and not the syntactic computational system, with the consequence that learners' morphophonological productions do not always coincide with target-like surface forms. On the other hand, there are those who believe that there is a malfunction in the syntactic computational device itself, particularly certain feature properties of 
functional categories, suggesting that the L2 grammar is essentially impaired and that this causes the optionality; this is known as the Impaired Representation Hypothesis (Meisel, 1997; Hawkins, 2000; 2001; Franceschina, 2001).

Prévost and White (2000) have investigated these issues in naturalistic L2 learners of French by examining the distribution of finite and non-finite verb forms in finite and non-finite contexts. White (1996) and Prévost (2003) have investigated them by examining the interaction of pronominal and clitic subjects with finite and non-finite forms in child L2 learners and in instructed Anglophone adults in Quebec respectively. All have argued that if there is a contingency between finite verb forms and finite syntactic contexts, and between the use of clitic subjects and finite verb forms, then it must be assumed that an Inflection (I) (or Tense (T)) category specified for finiteness is abstractly represented in syntactic structure. If there is no such contingency, that would be consistent with the absence of $\mathrm{I} / \mathrm{T}$.

This study examines the interaction between negation and finite/ non-finite verb forms, and subjects (null, full DP and clitic) and finite/non-finite verb forms in the development of L2 French by Englishspeaking adolescents exposed only to classroom input. The question that is addressed is whether development in such learners provides support for one or other position on the availability and nature of functional categories in early L2 acquisition.

\section{Negation and functional categories}

In current linguistic theory Universal Grammar (Chomsky, 1995) consists of invariant computational devices: a syntactic component, a semantic component and a morphological component. It also consists of a universal set of different types of features: semantic, phonological and syntactic. Syntactic features can be divided into interpretable (e.g. the phi-features of nouns: person, number and gender) and uninterpretable (e.g. the Extended Projection Principle feature that forces subjects to raise to spec TP). Languages differ in their choices from these sets of features. Different choices of uninterpretable syntactic features entail differences between languages that have traditionally been called differences in parameter setting. 
It is well known that the property of negation interacts with parameterized properties of verbal functional projections. In French, $\mathrm{T}$ has a strong uninterpretable feature that forces $\mathrm{V}$ to raise in order to delete it so that the feature is no longer visible at LF. In English, the corresponding feature of $\mathrm{T}$ is weak and $\mathrm{V}$ raises covertly (after spell-out). A number of differences in word order between French and English are therefore the result of verb movement. In French, the finite verb raises over negation and adverbs to T, while the non-finite verb remains in VP (Pollock, 1989), as illustrated in (1). ${ }^{1}$
1) a. Jean ne
regarde $_{\mathrm{i}}\left[_{\mathrm{NegP}}\right.$
pas $\mathrm{t}_{\mathrm{i}}\left[{ }_{\mathrm{VP}} \mathrm{t}_{\mathrm{i}}\right.$
la television]].
Jean Neg
watch
not
the television

'Jean doesn't watch the television.'
b. Jean regarde ${ }_{\mathrm{i}}\left[{ }_{\mathrm{VP}}\right.$ Souvent $\left[{ }_{\mathrm{VP}} \mathrm{t}_{\mathrm{i}}\right.$ la television]].
Jean watch often the television

'Jean often watches the television.'

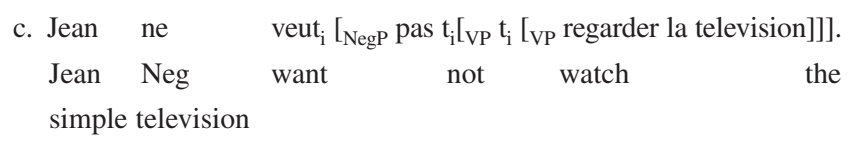

'Jean doesn't want to watch the television.

In line with Pollock (1989), we assume that negation heads its own projection NegP, that pas (like English 'not') is generated in the specifier position of NegP, and that ne is the head of NegP. As the finite verb raises to $\mathrm{T}$, the head ne cliticizes to the verb and raises with it. ${ }^{2}$ In contrast, English requires insertion of the 'dummy' auxiliary do as a last resort operation.

\section{Inflection in $\mathrm{L} 1$ and the acquisition of negatives}

Research has shown that while L1 learners alternate between finite verb forms and non-finite verb forms in main clauses (Optional Infinitives; OIs), the forms produced are structurally constrained (Rizzi, 1994; Wexler, 1994; 1998). For example, OIs in the acquisition of L1 French do not occur before negative pas or with subject clitics, but they are quite often used with null subjects (Pierce, 1992), and with strong forms of pronouns moi 'me' and toi 'you' (see also Harris and Wexler, 1996; 1998). Furthermore, studies of early learners of L1 French show contingency

\footnotetext{
${ }^{1}$ In this article due to the nature of the data, i.e. from early learners, we only cover the placement of finite verbs in relation to the negative particle pas.

${ }^{2}$ In spoken French $n e$ is often not realized.
} 
between finiteness and verb raising, where finite verbs precede negation and non-finite verbs follow negation, e.g. marche pas 'walks not', pas manger la poupée 'not eat-INF the doll' (Pierce, 1992). Additionally, if they use agreement morphology, L1 learners use it correctly, i.e. the subject will agree with the finite verb (Harris and Wexler, 1996).

According to Wexler (1998), certain properties of child grammars can only be adequately explained by a theory of growth or maturation, linked to a claim that language grows in the mind/brain. The OI stage is then due to the immature state of the child's grammar, as she or he is not yet cognitively mature (Wexler, 1994; 1998). Although the grammar is at all times consistent with Universal Grammar and there is full access to functional categories, it may be constrained by different principles to those operating in adult grammars. One such principle falls out of the AGR/TNS Omission Model (ATOM) of Schütze and Wexler (1996), which suggests that in children's grammar AGR or TNS (assumed to be independent functional projections) can optionally be left out. The reason why such optionality can occur is that child grammars are subject to the Unique Checking Constraint (UCC) (Wexler, 1998). This allows an interpretable feature to check and delete an uninterpretable feature only once (whereas in mature grammars the same interpretable feature can freely check any number of uninterpretable features, where such checking is possible). On standard assumptions, both AGR and TNS have uninterpretable D features that need to be deleted by the subject DP during the course of the derivation. If, however, child grammars include the UCC, one of the uninterpretable D features will remain unchecked, in violation of the principle of Full Interpretation. The solution to this problem that child grammars seem to adopt is to allow one of AGR or TNS to be optionally omitted. As the child matures, the UCC disappears.

If root infinitives occur in child grammars as a result of the presence of certain principles that disappear with maturation, we would not expect to find OIs in our data from adolescent L2 learners as this would be evidence against maturation being the cause of OIs. Adolescents are cognitively mature and if their grammars did display root infinitives then we would not expect them to have the same properties as L1 root infinitives. If they did have the same properties then the maturational account of root infinitives would be disconfirmed and OIs could be assumed to be an effect of the way linguistic development occurs. 


\section{Inflection in L2 and the acquisition of syntactic properties}

Many researchers assume that verb movement is the effect of strong features in I/T, but there has been disagreement about the relationship between abstract feature strength and overt morphological paradigms. Some L2 researchers propose a close connection between the two (Eubank, 1994; Vainikka and Young-Scholten, 1994; 1996). In this view, absent overt morphology would imply missing functional categories in $\mathrm{T}$ or impaired feature values. Others argue that abstract functional features are separated from surface morphology: the 'separation hypothesis' (Lardiere, 1998; 2000; Sprouse, 1998).

The two main proposals for explaining the optional omission of verbal inflections in L2 learners' grammars are linked to the non-separationist and separationist views of the relation between syntax and morphology. A non-separationist view leads to the claim that where early-stage L2 learners omit inflectional morphology, their interlanguage grammars have impaired syntactic representations, either globally (Meisel, 1997) or in terms of certain properties of their functional categories (Eubank, 1994; Beck, 1998). A related proposal is that certain feature values cannot be changed or activated in L2 acquisition (Tsimpli, 1998; Hawkins, 2000; Franceschina, 2001). Hawkins claims that once uninterpretable feature values are activated for functional categories in L1, the L2 learner is restricted to these feature values. There is therefore a critical period for the selection of parameterized formal features (Hawkins, 2000: 80). This position has been referred to as the Impairment View (Prévost and White, 2000a; Ionin and Wexler, 2002). For proponents of this view, an impairment accounts for the use of non-finite forms in finite contexts by L2 learners. Frequent omission of verbal inflections indicates functional categories are impaired. One of the main arguments against the Impairment View is that if functional categories are missing or impaired, then placement of finite forms and non-finite forms would be random and inflectional morphology would be used incorrectly (Prévost and White, 2000a).

In contrast to the Impairment View is the possibility that the malfunction is in a peripheral component of the language faculty. L2 functional categories and feature values are attainable and the problem with L2 grammars lies at the interface between abstract features and morphological forms (Lardiere, 1998; 2000), or in selecting lexical items for derivations (Prévost and White, 2000a; 2000b). It is these researchers 
that subscribe to the 'separation hypothesis' as outlined above. For Prévost and White (2000a), the non-finite forms that occur in finite contexts are actually 'default' finite forms and they can occur in both nonfinite and finite positions. Using the Distributed Morphology Approach of Halle and Marantz (1993), Prévost and White (2000a: 127) suggest that 'learners have acquired the relevant features for terminal nodes in syntax' but that some features of a lexical item may be partially specified (or unspecified) (Prévost and White, 2000b: 23). Although the features of lexical items may not be an exact match for the features of a terminal node, they will form a subset of the features on the functional node. Nonfinite forms are underspecified for finiteness in L2 grammars and can be inserted into the node with a [+finite feature] but the reverse is not possible because finite forms are specified [+finite] and cannot be inserted into a terminal node specified for the feature [-finite]. These 'default' finite forms therefore exhibit the behaviour of a finite verb in regard to the placement of negation, raising above NEG, and occurring with subject clitics (only finite verbs can co-occur with subject clitics). Unlike L1 acquisition, the MSIH predicts no correlation between null subjects and OIs and no contingency between subject clitics and finite verbs (Prévost and White, 2000b). Instead it argues that if non-finite verbs are really being used as 'default' forms for finite verbs then subject clitics will occur with them as these root infinitives are not truly non-finite.

\section{Previous studies of the $\mathrm{L} 2$ acquisition of negative clauses}

Negation is a much-studied property of L2 grammars and merits continued study because it can provide insight into the issue surrounding functional categories and feature values. In his 1997 article, Meisel compares L1 acquisition and L2 acquisition of colloquial French and German. The L2 learners are native speakers of Spanish. Based on data from two earlier Sources - Noyau (1982) and Trévise and Noyau (1984), both cited in Meisel (1997: 243) - his analysis covers 10 adult Spanish L1 learners of L2 French. There is only one instance of preverbal pas in the whole corpus and Meisel accounts for the occurrence of preverbal ne without pas by suggesting that it is induced by language instruction and then 'further stimulated by similarities between L1 and L2' (Meisel, 1997: 244). For Meisel, as pas does not systematically occur before non-finite verbs as in L1 acquisition then this confirms that the correlation between 
finiteness and negative placement found in L1 acquisition does not hold in L2 learners. To further test the hypothesis that there is a correlation between the syntax of negation and movement of finite verbs, Meisel analysed data from learners at an earlier stage of acquisition, two Spanish learners whose data was collected as part of the ESF project (Meisel, 1997: 245). He concludes that neither learner uses finiteness productively as finite forms and non-finite forms do not vary according to grammatical context. From these two datasets Meisel concludes that L2 learners resort to different kinds of strategies to L1 learners, thus confirming his 'global impairment' view of L2 acquisition.

Hawkins (2001) examines Devitt's data (1992: 103-05) of two children acquiring French naturalistically. These children were aged 11 and 8 . The data showed that the children were apparently raising the verb past pas as neither girl produced forms of the type pas followed by a verb, e.g. *elle pas aime le film '*she not likes the film'. This was an indication of early knowledge of negative placement. Similarly, Herschensohn (1998) in a study of American University students learning L2 French at intermediate level collected production data that showed $100 \%$ correct placement of finite verbs with negative pas.

Prévost and White (2000a; 2000b) re-examine the ESF data of Abdelmalek and Zahra, and report that finite verbs were consistently placed before the negator pas. They suggest that verb movement has taken place and functional categories and feature values are present in the learners' grammars. They report that correct verb placement is observed at the very earliest stages and conclude that appropriate feature strength is known from very early on. They also found that non-finite verbs appear before negators but that finite forms do not occur after the negator, thus providing evidence for their view (MSIH) as discussed above.

A study of university level learners of L2 French by Hawkins et al. (1993) using a grammaticality judgement test, reports that both intermediate and advanced groups are accurate at locating lexical verbs with negatives but not so accurate with adverbs and quantifiers. This result led Hawkins (2001) to suggest that the learners are not raising the verb as the result of establishing that the features of $\mathrm{T}$ are strong, but because they are sensitive to the complement selectional properties of heads. He argues that as Neg is followed by an empty head and the lexical verb is located to the left of Neg, the learners are forced to project $\mathrm{T}$ above 
NegP so that the verb can raise and then Neg can be followed by an empty head. This would imply that the raising of the verb is unconnected to the strength of features in $\mathrm{T}$ but it is brought about by other processes within UG (Hawkins, 2001: 111).

In the current study, which is reported in Section VI, by exploring early learners' use and placement of finite verbs, we wanted to assess whether functional categories were present and feature values known by testing:

- whether our learners showed correct placement of finite verbs with respect to the negative pas;

- whether the placement of finite verbs was random or not and whether learners' use of finiteness inflections was appropriate or not;

- whether the learners used subject clitics with finite forms of the verbs (which would imply that the verb is genuinely finite and $\mathrm{T}$ is projected); and

- whether they used null subjects with non-finite forms (which would suggest that the forms are truly non-finite as in L1 acquisition).

\section{The study}

This was a cross-sectional study involving 60 L1 English learners of French L2 aged 13-16, with 20 learners from each of three school years, with exposure to classroom instruction approximately as follows: Year 9 195 hours, Year 10283 hours and Year 11380 hours. None of the learners had spent any significant amount of time exposed to the L2 outside the classroom. The main oral elicitation task used here consisted of a card with the name and picture of a famous person on it accompanied by 22 picture prompts, showing activities either with a cross or a tick next to them. The learner was asked (in L1) to describe what the famous person does and does not do, according to the picture prompts provided, so that the researcher could guess who the famous person was. The learners were unprompted apart from the pictorial prompts. ${ }^{3}$ They gave one sentence for each picture, each requiring a finite verb. For example, target sentences for David Beckham were: il ne travaille pas dans un bureau ('he doesn't work in an office') from a picture, with a cross next to it, of somebody 
working in an office and il joue au football ('he plays football') from a picture of somebody playing football with a tick next to it. Each learner produced a mean of just over 9 obligatory negative contexts and also a mean of 9 verb types in negative contexts. (As there were very few repetitions of the same verb type within individual learners, the results are actually based on the number of tokens.) We transcribed any verbs ending in the sound $[\mathrm{e}]$ as non-finite unless there was evidence to the contrary. The data was transcribed using CHAT (MacWhinney, 2003) procedures.

Evidence of the following was searched for:

- some form of negation without a verb, e.g. pas + sport, which would provide evidence for projection of only lexical categories. If learners are merging negation and lexical items, this would be consistent with the absence of functional projections (for an alternative view, see Lakshmanan, 19984);

- ne $\mathrm{V}[+\mathrm{fin}]$ pas or ne pas $\mathrm{V}[+\mathrm{fin}]$. If there was little or no use of the latter, it would suggest that the distribution of finite forms is syntactically constrained and not random;

- use of pronominal subjects with finite verbs only, and absence of intervening constituents between pronominal subjects and finite verbs, as this would indicate they were true clitics and not just weak pronouns.

Productivity was calculated for each learner in terms of percentage occurrence in obligatory contexts. A number of the obligatory contexts elicited what appeared to be idiosyncratic productions and were categorized as 'other' (e.g. one learner produced many varieties of clause external negations for example, *il prendre le bus pas '*he takes the bus not', *le vin ne pas '*the wine not' *je mange non '*I eat no', and one learner used n'est-ce pas 'isn't it' throughout). ${ }^{5}$ These accounted for means of $17.5 \%, 10.5 \%$ and $5.7 \%$ of obligatory contexts for learners in Years 9, 10 and 11 respectively, and are not presented in Table 1.

${ }^{4}$ Lakshmanan (1998) reports instances of verbless utterances in child L2 data, e.g. 'This is the boy for the cookies 'in place of' This is the boy eating the cookies'. She suggests that although the learners do not initially project VP, 'boy for the cookie' is a projection containing lexico-functional categories, as 'for' acts as a case assigner.

${ }^{5}$ It is worth noting that our learners, perhaps due to the nature of classroom input, usually produced ne in their negative utterances, unlike in native speaker French or French L1 Acquisition (Pierce, 1992). 
198 Functional categories in early French L2

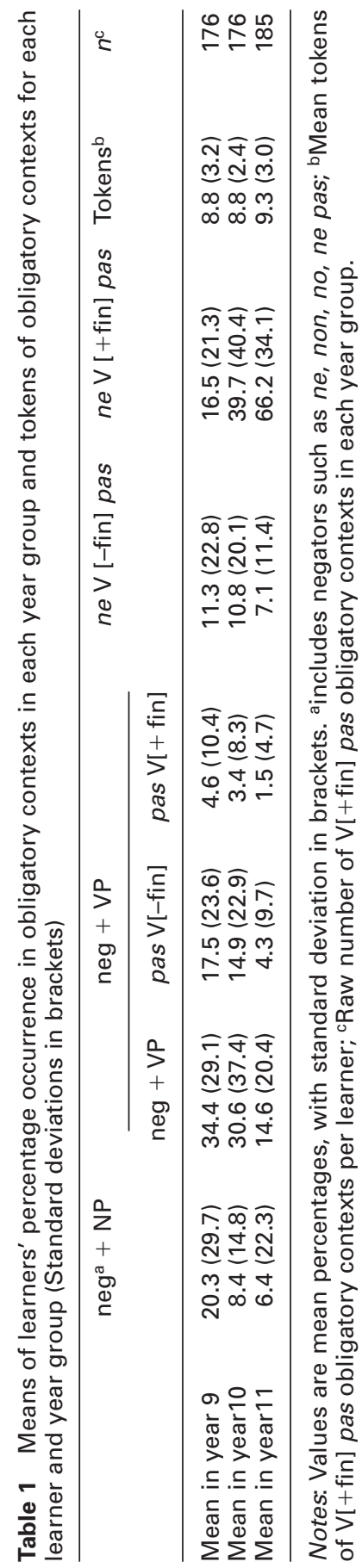


Although care was taken to ensure that the language elicited was indicative of learners' productive use,rather than a reflection of targetlike rote-learned phrases ('chunks') that are a prominent feature of language amongst these learners (Myles et al., 1999), this was not always possible. In order to account for this, the proportion of $n e$ $\mathrm{V}[+\mathrm{fin}]$ pas combinations that we could not be sure represented productive use was calculated and is discussed later.

In addition to the data collected and analysed as above, data was also analysed from Mitchell \& Dickson (1997), from learners who had approximately 40 hours exposure to classroom instruction. This data and analysis is discussed at the relevant point in the presentation of the results.

\section{Results}

Descriptive statistics of the results are shown in Table 1. These are presented here as the means of learners' 'percentage of production out of obligatory contexts'. This was calculated for each year group to enable the use of inferential statistics (see Tables 2 and 3) to compare year groups as a broad indication of trends in the initial analysis. Year groups were considered as possible stages of developmental progression as this was a fairly objective measurement of exposure to L2 input. However, the high standard deviations seen in Table 1 reflect the variability between learners' production of each obligatory context type. For example, there was a wide range of scores for the production of $\mathrm{V}[+\mathrm{fin}]$ pas in each year group (with a few learners producing many and some producing none). ${ }^{6}$ As it is likely that year groups do not reflect actual stages of morphosyntactic development, total productions of all learners in each year group were not amalgamated for the presentation of the results, as means and standard deviations were considered to provide more information for current purposes. This issue is also raised later.

Statistical analyses were carried out on changes in several measures across year groups:

- \% negation + noun phrase (no verb) out of obligatory contexts: a statistically significant reduction over the years could suggest the

${ }^{6}$ The high standard deviations also reflect the fact that the data was not normally distributed (according to the Kolmogornov-Smirnov test) as they were heavily positively skewed. Non-parametric tests were therefore used. 
Table 2 Results of Kruskall-Wallis $\mathrm{H}$ tests to assess differences between all year groups on four measures

\begin{tabular}{rrrrr}
\hline & Neg NP & Neg VP & V[-fin] pas & V[+fin] pas \\
\hline Chi-Square & 6.071 & 5.367 & .264 & 16.014 \\
df & 2 & 2 & 2 & 2 \\
Asymp. Sig. $(p)$ & .048 & .068 & .877 & $<.001$ \\
\hline
\end{tabular}

gradual projection of functional categories, as there is no evidence of hierarchical phrase structure;

- \% negation + verb phrase (and, specifically \% negation V[-fin]) out of obligatory contexts: a statistically significant decrease would indicate a change in the learners' grammars regarding the status of functional categories;

- \% ne+finite verb+ pas out of obligatory contexts: a statistically significant increase over the years would suggest the gradual projection of functional categories with correct feature values.

The Kruskal-Wallis $\mathrm{H}_{\text {test }}{ }^{7}$ (Table 2) suggested there were statistically significant differences overall between the three year groups for the neg $+\mathrm{NP}$ and the $n e \mathrm{~V}[+\mathrm{fin}]$ pas measures and that the difference in neg $+\mathrm{VP}$ is approaching significance. ${ }^{8}$ In order to locate where these differences lay in terms of year groups, the Mann-Whitney U test was used to compare year group pairs and the results are presented in Table 3.

\section{Verbless utterances $(\mathrm{Neg}+\mathrm{NP})$}

Verbless utterances include tokens such as *je ne pas icecream '*I not icecream', *elle non télévision '*she no television', *il pas fils '*he not son'. It should be emphasized that although such utterances were produced on average in $20 \%$ of contexts where a finite verb would be obligatory for native speakers, this figure has a large standard deviation.

\footnotetext{
${ }^{7}$ This test is suitable for comparing $2+$ unrelated samples (the non-parametric equivalent of the oneway ANOVA test), and is necessary to compensate for the increase in the probability of Type 1 errors involved in carrying out the subsequent multiple paired comparisons.

${ }^{8}$ As the Kruskall-Wallis tests non-directional hypotheses (i.e. the presence of a difference, not whether this is an increase or decrease), this $p$ value is considered to be sufficiently approaching statistical significance to carry out paired comparisons.
} 
Table 3 Results of Mann-Whitney $U$ tests showing differences between pairs of year groups in three measures

\begin{tabular}{rrrr}
\hline & Neg + NP & Neg + VP & V + fin pas \\
\hline Year 9 and 10: & & & \\
Mann-Whitney U & 150.000 & 169.000 & 131.500 \\
Wilcoxon W & 360.000 & 379.000 & 341.500 \\
Sig. & -1.503 & -848 & -1.905 \\
Y & .092 & .207 & .032 \\
Years 10 and 11: & & & 129.000 \\
Mann-Whitney U & 174.000 & 159.500 & 339.000 \\
Wilcoxon W & 384.000 & 369.500 & -1.931 \\
Z & -.925 & -1.140 & .028 \\
Sig.* & .248 & .139 & 51.500 \\
Years 9 and 11: & & & 261.500 \\
Mann-Whitney U & 124.000 & 110.500 & -4.075 \\
Wilcoxon W & 334.000 & 320.500 & $<.001$ \\
Z & -2.365 & -2.455 & .007 \\
Sig. & .020 & & \\
\hline
\end{tabular}

Notes: *The $p$ values given are for a one-tailed test, the hypotheses being that Neg NP and Neg VP would decrease and V[+fin] pas would increase.

The use of verbless utterances decreased markedly in Years 10 and 11 and the $6.36 \%$ in Year 11 were mainly due to one learner. The decrease in neg +NP was statistically significant between Years 9 and 11 (see Table 3).

The use of a negator used before a NP in a verbless utterance is consistent with evidence from an earlier study (Mitchell \& Dickson, 1997), which collected oral production data in English secondary schools of learners of French in Years 7 to 9 (complete beginners to approximately 235 hours of instruction). Using this data, Myles (2005) found that 50\% of Year 8 learners' utterances in an oral narrative task were verbless (Myles, 2005: 15). For the current study, an analysis was carried out of data from Year 7 learners (with about 40 hours of instruction). The learners carried out a paired information gap in which they described and asked questions about pictures of people with the aim of drawing each other's pictures. It was found that out of a total of 332 tokens of obligatory contexts for verbs (including declarative, negative and interrogative contexts) amongst 67 learners, $80.7 \%$ were verbless. This figure is considered to be conservative as, although the analysis excluded utterances that were considered to be rote-learned phrases (see below 
for a discussion of the criteria used), the vast majority of remaining verbs were in phrases such as il a les cheveux bruns / les yeux bleus and il est grand/petit, also likely to constitute expressions rote-learned during a popular 'topic' in the curriculum. In addition, other data from these Year 7 learners suggest that other types of functional categories are absent, e.g. determiners, including pronouns, although a detailed analysis of other categories has not been carried out. Taking the evidence from these three studies together, the high proportion of merged neg + NP constructions is consistent with learners having grammars which lack a functional $\mathrm{T}$ projection altogether.

\section{Pre-verbal negation (Neg $+V P$ and specifically Neg $+V[-f i n])$}

The number of expressions where the entire negator was preverbal in Year 9 was more than halved in Year 11 (and this was statistically significant; see Table 3). Throughout, there were very few instances of pas V[+fin] (Year 9: 4 learners; Year 10: 3 learners; Year 11: 2 learners). Unlike the data analysed in Meisel (1997), we did find examples of pas occurring before non-finite verbs, e.g. *il ne pas jouer au basketball '*he not play basketball'. However, the occurrence of pas V[-fin] decreases over the year groups and is almost negligible in Year 11 (just $4.34 \%$, with most learners never producing this pattern). This decrease was statistically significant (according to a one-tailed Mann-Whitney U test, ${ }^{9} 131.000, \mathrm{Z}-2.076, p=0.032$ ). There was a clear drop from Year 9 to Year 11 in the use of ne pas as one fixed negator where the parts do not separate, for example *elle ne pas fumer '*she not smoke', *elle ne pas aller au piscine '*she not go to the swimming pool', *il ne pas prendre le bus '*he not take the bus'. The use of ne pas as a fixed preverbal negator could indicate a lack of functional projections, as there is no evidence of $\mathrm{T}$ being projected for the verb to raise to (For an alternative position, see Haznedar, 199710). These findings could imply a significant change in the learners' grammars across the years.

\footnotetext{
${ }^{9}$ This test is suitable for comparing pairs of unrelated samples.

${ }^{10}$ In a study of a Turkish boy learning English from aged 4: 3 years, Haznedar (1997) claims that although his first utterances are of the type 'Yes ball playing', his grammar contains functional categories and they have been transferred from the L1 along with their headedness.
} 


\section{Post-verbal negation (ne V[+fin] pas)}

The only measure which increased statistically significantly between each year was the use of finite verbs before pas, suggesting these learners seem to be progressing towards target-like use of negation with finite verbs, i.e. that functional categories are in place with correct feature values.

\section{Mutual exclusivity}

We also examined the expression of negation within individual learners and found that learners who produced ne $\mathrm{V}$ pas (whether the verbs were inflected or not) did not also produce verbs after pas. This clearly suggests a difference between L1 learners' use of non-finite verbs in finite contexts and these adolescent L2 learners' use of non-finite verbs. From these results it seems that the L2 learners are not using OIs: in obligatory finite contexts individual learners do not alternate between pas followed by a non-finite verb and finite verb followed by pas. This suggests the existence of separate stages in grammatical development: an early stage without functional categories, in which, if verbs are present, negation is preverbal and a later stage with functional categories, in which negation is post verbal. Of the learners who produced verbs (excluding chunks and idiosyncratic productions) (i.e. 50 out of the 60 learners), 35 of them $(70 \%)$ produced either entirely preverbal or postverbal negation. The remaining 15 learners showed a clear preference for one of these, producing just one or two examples of an 'alternative' production, which, on second analysis, were borderline cases for the chunk and idiosyncratic categories or could be accounted for by possible transcription inaccuracies. Expressed another way, across the whole dataset, there were 29 tokens (i.e. just $5.4 \%$ of the total obligatory contexts produced) which were not in line with individuals' 'preferred' verb position.

\section{Possible caveat: productive use?}

We needed to be confident that the ne $\mathrm{V}[+$ fin] pas combinations constituted productively inflected verbs, rather than unanalysed chunks, rote-learned in class. Myles et al. (1999) lay out a set of criteria for identifying 'chunks' that have been used here. The one most frequently 
Table 4 The use of chunks in obligatory ne V[+fin] pas contexts

\begin{tabular}{llll}
\hline & $\begin{array}{l}\text { Number of chunk } \\
\text { V[+fin] pas }\end{array}$ & $\begin{array}{l}\text { Total number of } \\
\text { V[+fin] pas }\end{array}$ & $\begin{array}{l}\text { Percentage chunk out of } \\
\text { V[+fin] pas }\end{array}$ \\
\hline Year 9 & 18 & 34 & 52.9 \\
Year 10 & 43 & 64 & 67.2 \\
Year 11 & 82 & 122 & 67.2 \\
\hline
\end{tabular}

applied was that many of the utterances were grammatically accurate but semantically misplaced (e.g. je n'ai pas le vin 'I haven't got the wine' for 'he doesn't drink wine'). Je n'aime pas 'I don't like' was included in the count of chunks where learners tended to use them as their default response, giving no evidence that they could negate other lexical items. The results are presented in Table 4.

Although this could weaken claims that the increase in $n e \mathrm{~V}[+\mathrm{fin}]$ pas reflects an emergence of functional categories and feature values within the developmental stages represented here, the number of "nonchunk' ne V[+fin] pas combinations, i.e. those that could certainly be considered as productive use, increased over the years and is presented in Table 5.

A paired comparison suggested that the increase between Years 9 and 11 was significant at the $90 \%$ confidence level, suggesting a tendency towards learners projecting functional categories (Mann-Whitney U 157.500, $p=0.097) .{ }^{11}$ The productive use of $\mathrm{V}[+\mathrm{fin}]$ pasin Year 9 is attributable to just two learners, and may indicate that these two learners project functional categories including T. As acknowledged earlier, 'Year 9' is not proposed as a strict developmental stage nor are Year 9 learners complete beginners (for analysis of data from earlier learners,

Table 5 Productive use of ne $\mathrm{V}[+\mathrm{fin}]$ pas

\begin{tabular}{lllll}
\hline & Total & Mean & St. dev. & $\begin{array}{l}\text { Percentage of total } \\
\text { contexts produced } \\
\text { in year group }\end{array}$ \\
\hline Year 9 & 16 & 0.8 & 1.54 & 9.1 \\
Year 10 & 21 & 1.05 & 2.28 & 11.9 \\
Year 11 & 40 & 2.00 & 3.18 & 21.6 \\
\hline
\end{tabular}

\footnotetext{
${ }^{11}$ This means that $90 \%$ of the time we could be confident that the increase between Years 9 and 11 would be significant. This is considered to be evidence of a trend, although it is acknowledged that this does not meet the (arbitrary) level set by some social scientists.
} 
Table 6 Correlation of use of chunks with productive use of ne V[+fin] pas within individual learners

\begin{tabular}{lcll}
\hline & Spearman's rho & $p$ value & $n$ \\
\hline Year 9 & 0.119 & 0.617 & 20 \\
Year 10 & -0.020 & 0.932 & 20 \\
Year 11 & -0.341 & 0.141 & 20 \\
Overall & -0.071 & 0.592 & 60 \\
\hline
\end{tabular}

see below). A second analysis of the other examples of $\mathrm{V}[+\mathrm{fin}]$ pas in Year 9 (one or two from five learners) suggested that these were probably chunks (e.g. je n'aime pas 'I don't like').

In addition, the correlation between the number of chunks individual learners produced and their ne $\mathrm{V}[+\mathrm{fin}]$ pas constructions that can be confidently claimed to be productive use (e.g. il ne joue pas 'he doesn't play', elle ne mange pas 'she doesn't eat', elle ne travaille pas 'she doesn't work', elle ne fait pas 'she doesn't do/make', il ne regarde pas 'he doesn't watch') is not statistically significant, as shown in Table 6.

This suggests that those learners who do produce 'creative' finite verbs are not also producing verbs that can only be considered as chunks. Furthermore, although a mean of $47.87 \%$ of the $n e \mathrm{~V}[+$ fin] pas constructions could not be categorized confidently as creative language use, the standard deviation was large (46.57), as many learners did not rely on chunks at all and some learners did almost entirely.

\section{Learners who look like they may be raising the verb}

In the negative oral elicitation task there were only six learners who seemed to consistently inflect and move the verb, and it is with these learners that we could be completely confident they were not relying on unanalysed chunks (their productions consisted of a range of lexical verbs). We therefore analysed their declarative sentences in the negative elicitation task and their productions in the other three tasks carried out in the same project (semi-spontaneous oral production tasks; details in Appendix 1). This was to confirm whether learners' production of finite inflections in the verb-raised position in the negative oral elicitation tasks did indeed represent finite forms, and also to explore their use of a range of agreement and tense features. 'Chunks' were excluded from the count of finite verbs. The results are shown in Table 7. 
Table 7 Tokens in obligatory contexts over 4 tasks of learners who produced over $63 \%$ ne $V[+$ fin] pas in obligatory contexts

\begin{tabular}{lccccccc}
\hline $\begin{array}{l}\text { Learner } \\
\text { ID and } \\
\text { year }\end{array}$ & $\begin{array}{c}\text { Finite } \\
\text { verb } \\
\text { contexts }\end{array}$ & $\begin{array}{c}\text { V }[+ \text { fin] } \\
\text { ( in V[+fin] } \\
\text { contexts) }\end{array}$ & Chunks & Otherb & & $\begin{array}{c}\text { Non- } \\
\text { target }\end{array}$ \\
\hline 26 (Year 10) & 121 & $48(39.67)$ & 31 & 5 & 0 & 6 & 23 \\
\hline 29 (Year 10) & 116 & $80(68.97)$ & 18 & 11 & 0 & 5 & 2 \\
42 (Year 11) & 58 & $19(32.76)$ & 21 & 11 & 4 & 0 & 1 \\
45 (Year 11) & 113 & $91(80.53)$ & 2 & 11 & 0 & 4 & 4 \\
48 (Year 11) & 133 & $105(78.95)$ & 24 & 4 & 0 & 3 & 0 \\
49 (Year 11) & 134 & $122(91.04)$ & 7 & 4 & 1 & 0 & 0 \\
\hline
\end{tabular}

Notes: anot including 'chunks' and 'other', but including all inflections, including those few occasions where learners appeared to inflect but used a non-target-like inflection (seen only for expression of tense or in irregular verbs); ${ }^{b}$ given to learners in glossary or, very occasionally, a clear transliteration.

The data from Learner 26's negative elicitation task were not supported by data from these other three tasks, which suggests that the learner's verb inflection is not consistent. As well as relying heavily on chunks, this learner produced many verbless structures thus not providing clear evidence that functional categories are present in the grammar with the appropriate feature values.

Although the $32 \% \mathrm{~V}[+\mathrm{fin}]$ in obligatory contexts looks small for Learner 42, in fact this learner made attempts to inflect for number (e.g. nous allons 'we go') and used a verb type in target-like non-finite and finite forms. It is important to note, as seen in Table 7, that where learners do not have $100 \%$ finite verbs in obligatory contexts, only a very few verbs were actually non-finite: the remaining instances were expressed using chunks or were counted as 'other', i.e. from the glossary. For example, Learner 42 only used a non-target non-finite verb once, but simply displayed an over-reliance on chunks. Although this may make the emergence of functional categories difficult to assess, it does not disprove it.

All the learners (except 26) produced finite verbs consistently across all four tasks. Learner 29 produced 9 ne $\mathrm{V}[+\mathrm{fin}]$ pas tokens in these other tasks, made 4 uses of the non-finite form in target-like contexts, and 7 attempts to inflect for tense. Learner 45 showed clear evidence of using target-like (and non-target-like) finite forms in order to express number, e.g. nous faisons 'we do/make', nous visitons 'we visit', nous nageons 'we swim', qui sont 'who are' and to express tense, e.g. je visiterai 'I will visit', j'ai visité 'I visited/have visited', made 3 uses of non-finite forms 
(3 types) in target-like contexts and one ne $\mathrm{V}[+$ fin] pas. Learner 48 produced 4 ne $\mathrm{V}[+\mathrm{fin}]$ pas constructions and 6 target-like non-finite verbs (all different types). Learner 49 made 11 inversions of verb + subject, 11 ne $\mathrm{V}[+$ fin] pas, 6 target-like non-finite uses, 14 attempts at inflecting in the past tense, and one clitic object pronoun.

In all of the oral production tests these six learners produced only a total of 18 examples of non-finite forms of the verb in finite contexts. These predominantly occurred in the story-retelling task (see Appendix 1), a task in which the processing demands are high. In line with the MSIH we argue that these are in fact default finite forms because they occur with subject clitic pronouns and behave syntactically like finite forms. Additionally the learners show evidence that they have acquired the fully specified finite forms of these same verb types. This suggests that knowledge of finiteness amongst these learners is not random.

\section{Verbal agreement}

In order to explore whether inflections were being used correctly, we counted the number of inflected verbs in the data from these six learners and then in each instance we looked at the person, number and tense inflection on the verb. We adopted Poeppel and Wexler's (1993) criteria (in Prévost and White, 2000a; Ionin and Wexler, 2002) for assessing correct agreement, i.e. to check that if a verb occurs with 3rd person singular morphology then the subject is 3rd person singular. Suppletive forms (avoir 'have', être 'be', aller 'go') were included in the count of inflected verbs, because, as Prévost and White observe, suppletive forms have features that also need to be checked and 'they are thus indicative of knowledge of agreement' (Prévost and White, 2000a: 120). The results are presented in Table 8.

Table 8 Learners' use of target-like inflection

\begin{tabular}{lccc}
\hline Learner ID & Inflected verbs & $\begin{array}{l}\text { Target-like } \\
\text { inflection }\end{array}$ & $\begin{array}{l}\text { Percentage of target-like } \\
\text { inflection in inflected verbs }\end{array}$ \\
\hline 26 & 48 & 47 & 97.9 \\
29 & 80 & 79 & 98.80 \\
42 & 19 & 19 & 100.0 \\
45 & 91 & 86 & 94.5 \\
48 & 105 & 103 & 98.1 \\
49 & 122 & 116 & 95.1 \\
\hline
\end{tabular}


Faulty agreement (e.g. 3rd person verb morphology with 2nd person singular subject) was not found in our data. Any non-target-like morphology is mainly due to absent agreement rather than incorrect agreement. Five occurrences of non-target-like finite forms involved the incorrect use of tense. Three other examples were of the type *les enfants fait ("*the children does') which probably indicate lack of knowledge of the suppletive form font 'do', not lack of knowledge of agreement, as elsewhere the learners correctly used the infinitive form faire.

\section{Use of subjects: further evidence of a change in our learners' grammars}

As discussed earlier, the MSIH predicts no correlation between null subjects and root infinitives and no contingency between subject clitics and finite verbs (Prévost and White, 2000b). Instead it argues that if non-finite verbs are really being used as 'default' forms for finite verbs then subject clitics will occur with them.

Although subject pronouns commonly appear in our data with nonfinite verbs, the status of these pronouns appears to change as learners progress. In some cases, particularly in Years 9 and 10 (see Table 9), the learners allow an intervening constituent pas between the pronoun and the verb, e.g. *il ne pas manger '*he not eat'. This suggests that the pronouns are not necessarily analysed as clitics in these cases, but rather that they have been analysed as weak pronouns as they would be in the learners' L1 English. However, as seen in Table 9, this tendency decreases substantially by Year 11 , from $14.6 \%$ in Year 9 to $2.7 \%$ in Year 11, possibly indicating a change in the nature of subject pronouns by this stage where they are now analysed as clitics. This development in the analysis of subject pronouns implies a qualitative change in the learners' grammars.

Table 9 Mean percentage use of subject pronouns with finite and non-finite verbs out of obligatory ne $\mathrm{V}[+$ fin] contexts

Mean percentage occurrence of pronoun ne pas $v[-$ fin] out of obligatory ne V[+fin]pas contexts (raw total ne V[+fin]pas contexts 
What we additionally find in our data is that if non-finite verbs are used in finite contexts then they appear with a subject pronoun. This constitutes further evidence against an L1 type OI stage for these learners (as in the L1 it has been found that non-finite verbs tend to be subjectless or occur with a full DP). ${ }^{12}$

\section{Summary}

This analysis has suggested that there was a clear increase from Year 9 to Year 11 in the correct use of finite verbs in relation to the negative particle pas. There were few occurrences of non-finite verbs in a raised position, particularly amongst learners with the most exposure to instruction. As these occurrences were only in the extended narrative task it was argued that the learners encountered some processing difficulties during that task. We also argued that as the verbs exhibited the behaviour of finite forms in terms of:

- occurring with a subject (unlike OIs in L1 acquisition);

- occurring with a subject clitic; and

- correctly placed in relation to pas,

then the apparent lack of inflection actually constituted a 'default' finite form. It was found that hours of exposure to instruction was not necessarily reflected in the state of the grammars (e.g. two Year 9 learners produced evidence of overt morphology and verb movement, one learner in Year 11 used verbless utterances and the learners who raised verbs to before pas were not necessarily from Year 11; (see Table 7).

Two potential arguments against this analysis could have been that the increase of correctly raised finite verbs was due to an increase in the number of rote-learned chunks that learners used, and/or that the negative elicitation task induced some kind of pattern production amongst learners, rather than genuine grammatical knowledge. However, an analysis of other tasks carried out by those learners who did demonstrate contingency between finiteness and verb raising showed that these learners did indeed produce finite forms in a range of linguistic contexts

\footnotetext{
${ }^{12}$ It should be noted that the nature of the task induced consistent use of pronouns rather than full DPs. Therefore for the learners who use root infinitives alongside finite forms, it is difficult to draw conclusions about their use of clitics with non-finite forms.
} 
(rather than default 'short' forms), that they inflected for a number of functions, that they demonstrated verb movement in other situations (e.g. finite lexical verb inversion in questions), that they used non-finite forms in non-finite contexts, that inflection was correct, if present, rather than random (a mean of $97.4 \%$ of inflections produced were target-like), and that they used full DPs and subject clitics with the finite verbs.

\section{Discussion and conclusions}

This article has presented data supporting four main observations, which are discussed in turn:

1) Functional categories not present in the initial state;

2) The functional category I(T) emerges fairly rapidly;

3) I/T fully specified when it emerges;

4) Non-target-like morphology is a mapping problem not a result of feature inpairment.

Three sources of data were used to suggest that functional categories are not present in the grammars in the very earliest stages of second languages acquisition. Data from Mitchell \& Dickson (1997) led to a conservative estimation that learners with 40 hours of exposure to classroom instruction produced $81 \%$ of utterances without verbs. Myles (2005) found that learners with about 100 hours exposure to instruction produce about $50 \%$ verbless utterances. The data examined in this study suggested that Year 9 learners, with 195 hours exposure, were found to produce approximately $20 \%$ verbless utterances and with 380 hours just $6.4 \%$. If this trend were extrapolated to learners with fewer than 40 hours exposure, the percentage of verbless utterances is likely to be greater than $81 \%$. In addition, even though after approximately 195 hours exposure some learners may appear to use verbs, many of these are suggestive of grammars without verb raising and without $\mathrm{T}$ for the verb to raise to (in Year 9 a mean of $34.4 \%$ of utterances, just under half of the utterances with a verb, were of the type neg + VP). These verbs are considered genuinely non-finite because they appear after the negative particle pas (or some other negator). Within this set of productions, additional evidence that the verb has not moved to a functional category was that in just under half of them $(14.6 \%$ of $\mathrm{V}[+\mathrm{fin}]$ pas contexts $)$ subject pronouns 
were separated from their verbal host by the negative particle pas, suggesting that these pronouns are not subject clitics. The data suggested that for 18 out of the 20 learners in Year 9, verb phrases are initially lexical phrases. This leaves about $30 \%$ of $\mathrm{V}[+\mathrm{fin}]$ pas obligatory contexts in year 9 (once idiosyncratic $(17 \%)$ and verbless (20\%) utterances have been excluded). Of this $30 \%$, about a third (i.e. $10 \%$ of obligatory contexts) had to be discarded as chunks. It was suggested that within the remaining 20\% (of which approximately half were of the type V[-fin] pas and half of the type $\mathrm{V}[+\mathrm{fin}]$ pas) two out of the 20 Year 9 learners had projected functional categories. (as emphasized earlier, the grouping of learners by school years does not necessarily represent uniform developmental stages; see, for example, the high standard deviations in Table 1). Other examples of post verbal negation within this $20 \%$ of obligatory contexts were considered to be due to borderline coding and transcription decisions, dispersed in isolated cases amongst five learners. We argue therefore that the data presented indicates a projection of lexical phrases, with an initial lack of functional categories in accordance with the Minimal Trees hypothesis (Vainikka and Young-Scholten, 1996).

Further evidence for the lack of functional categories in the first stages of learning is that learners who produced utterances like *il ne pas manger '*he not eat' did not also produce il ne mange pas or *il ne manger pas for 'he doesn't eat'. This suggests that there are two stages of grammar development, the former being without functional categories and the latter with, unlike in L1 acquisition where these two types of production can co-occur in the same emerging grammar due to the UCC.

\section{The functional category I/T emerges fairly rapidly}

This observation was based on four findings. A statistically significant decrease in the use of neg V[-fin] was found between Years 9 and 11 (a mean of $34.4 \%$ in Year 9 to $14.6 \%$ in Year 11 ; $\mathrm{Z}-2.455, p<0.01)$. The use of V[+fin] pas increases between Years 9 and 11 (a mean of 16.5\% in Year 9 to $40.5 \%$ in Year $11 ; \mathrm{Z}-4.075, p<0.001$ ). The productive (i.e. non-chunk) use of $\mathrm{V}[+\mathrm{fin}]$ pas increases between Years 9 and 11 (9.1\% in Year 9 to $21.6 \%$ in Year $11 ; \mathrm{Z}-4.075, p<0.1)$. The use of 


\section{Functional categories in early French L2}

subject pronouns separated from their verbal host decreases with exposure to the target language (from a mean of $14.6 \%$ in Year 9 to $2.7 \%$ in Year 11). Given that there is a difference of just 185 hours (approximately) exposure to classroom instruction between these two year groups, it is considered that these changes indicate a fairly rapid emergence of I/T once the functional category is projected. The data presented here therefore endorses the perspective that L2 grammars develop gradually (Vainikka and Young-Scholten, 1996; Hawkins, 2001), but that the appearance of functional categories is more rapid than in L1.

\section{I/T fully specified when it emerges}

There was a very low production of pas $\mathrm{V}[+$ fin] (a mean of $4.6 \%$ in Year 9 and $1.5 \%$ in Year 11). This suggested that the placement of finite verbs is not random. Rather, we noted a strong contingency between knowledge of finiteness and syntax indicated by the correct placement of pas and the correctly projected feature values of I/T. Unlike in grammars of children who are at the OI stage in L1 acquisition, our adolescent L2 learners' use of root infinitives suggested that the functional category $\mathrm{I} / \mathrm{T}$ is fully specified when it emerges. Learners who raised verbs did not also produce sentences of the type $* i l$ ne pas manger (i.e. they did not demonstrate knowledge of finiteness yet also sometimes omit T due to the UCC). In addition, the adolescent learners analysed here used non-finite verbs with subject pronouns (not with null subjects or full DPs as in L1 acquisition). This provides support for Wexler's claim that the OI stage in L1 acquisition can be accounted for by a developmental constraint in the child's grammar, i.e. the UCC (Wexler, 1998).

One potential limitation of this argument is that it could be claimed that the learners who appeared to place negatives correctly were drawing on other processes within UG, e.g. that Neg selects an empty head and it is this that causes them to raise the verb not the feature values of functional projections (Hawkins, 2001: 111). However, the data from our subset of learners suggests that this is not the case, i.e. six learners who consistently demonstrated correct negative placement also used correct agreement in a range of contexts, finite lexical verb inversion in questions and generally used tense correctly. 
4 Non-target-like morphology is a mapping problem, not a result of feature impairment

In the dataset as a whole there was some use of V[-fin] pas (a mean of $11.3 \%$ in Year 9 and $7.1 \%$ in Year 11). In the productions of individual learners occasionally both finite and non-finite forms were raised. Raised non-finite verbs were argued to be 'default' finite forms, in line with the MSIH (Prévost and White, 2000a). Evidence for this was that the use of finite and/or non-finite forms before pas almost entirely precluded the use of pas followed by non-finite verb (e.g. *il ne pas manger), i.e. learners had a strong tendency to either raise the verb or not. In addition, the default finite forms with missing surface inflection evinced the syntactic behaviour of finite verbs in that they always occurred with subject clitic pronouns (unlike in L1 acquisition where they can occur with null subjects).

Evidence for this was reinforced by data from other tasks completed by a subset of six learners, who produced very few examples of non-finite verbs in finite contexts (declarative, negative and interrogative) and, where used, they occurred with a full DP or a subject clitic. These learners also produced the fully specified 'finite' forms of the same verb types. These apparently non-finite forms were considered to be default finite forms. It seems that the rare occurrence of these default forms is caused by processing pressures and access to the finite forms is blocked. These 'default' forms are considered to be underspecified in terms of grammatical features but form 'a proper subset of features on the hosting node' (Ionin and Wexler, 2002: 101), and can thus be inserted into a node bearing a $[+$ fin $]$ feature so that checking can occur. This finding replicates the findings of Prévost and White (2000a; 2000b), even though the learner context was entirely different. Prévost and White's study was with naturalistic learners whose L1 was Arabic or Romance; in contrast our study is with instructed learners whose L1 is English. Thus the learner grammar characteristic of using default finite forms appears to be an important property of L2 acquisition and seems not to be affected by type of input or L1 of the learner.

Our data supports a Minimal Trees account of emerging L2 grammars in that in the earliest stages the data indicates projection of lexical phrases with an initial lack of functional categories. The data 
supports the gradual projection of functional categories (i.e., weak continuity) in emerging L2 grammars of French, but once the functional categories are projected - a process that appears to be a relatively rapid - the learners evince knowledge of finiteness as indicated by their correct placement of verbs in relation to the negative particle pas. The evidence suggests that there is no syntactic deficit in their grammars and this knowledge of finiteness appears to be irrespective of knowledge of the surface morphology of the verb, thus endorsing the 'separation' hypothesis (Sprouse, 1998; Lardiere, 2000; Prévost and White, 2000a). Our data lend important further support to the MSIH proposed by Prévost and White (2000a; 2000b), in that their findings have been replicated in a different learner context. So, we conclude that both Minimal Trees and MSIH are valid but reflect different stages of development.

\section{Acknowledgements}

The data was collected during an ESRC funded project no. R000223421 directed by Florence Myles at the University of Southampton. For further details of the project, see http://www.regard.ac.uk. Data is also used from an NFER and ESRC (award no. R000234754) funded project at the University of Southampton (Mitchell and Dickson, 1997). We thank the learners who participated in the projects, Florence Myles and Rosamond Mitchell for their advice and encouragement, and Roger Hawkins and two anonymous Second Language Research reviewers for their helpful comments. Any remaining errors are ours.

\section{References}

Beck, M.-L. 1998: L2 acquisition and obligatory head movement: Englishspeaking learners of German and local impairment hypothesis. Studies in Second Language Acquisition 20, 311-48.

Chomsky, N. 1995: The minimalist program. MIT press.

Devitt, S. 1992: Form and function in the developing verb system of five learners of French as a second language. Unpublished doctoral thesis, Trinity College, Dublin.

Epstein, S., Flynn, S. and Martohardjono, G. 1996: Second language acquisition: theoretical and experimental issues in contemporary research. Brain and Behavioural Sciences 19, 677-714. 
Eubank, L. 1994: Optionality and the initial state in L2 development. In Hoekstra, T. and Schwartz, B.D., editors, Language acquisition studies in generative grammar. John Benjamins, 369-88.

Franceschina, F. 2001: Morphological or syntactic deficits in near-native speakers? An assessment of some current proposals. Second Language Research 17, 213-47.

Grondin, N. and White, L. 1996: Functional categories in child L2 acquisition of French. Journal of Language Acquisition 5, 1-34.

Halle, M. and Marantz, A. 1993: Distributed morphology and the pieces of inflection. In Hale, K. and Keyser, S.J., editors, The view from building 20: essays in linguistics in honor of Sylvain Bromberger. MIT Press, 111-76.

Harris, T. and Wexler, K. 1996: The optional infinitive stage in child English: evidence from negation. In Clahsen, H., editor, Generative perspectives on language acquisition: empirical findings, theoretical considerations and crosslinguistic comparisons. John Benjamins, 1-42.

Hawkins, R. 2000: Persistent selective fossilisation in second language acquisition and the optimal design of the language faculty. Essex Research Reports in Linguistics 34.

2001: Second language syntax: a generative introduction. Blackwell.

Hawkins, R., Towell, R. and Bazergui, N. 1993: Universal grammar and the acquisition of French verb movement by native speakers of English. Second Language Research 9, 189-233.

Haznedar, B. 1997: L2 acquisition by a Turkish-speaking child: evidence for L1 influence. In Hughes, E., Hughes, M. and Greenhill, A., editors, Proceedings of the 21st Annual Boston University Conference on Language Development. Cascadilla Press, 245-56.

2003: The status of functional categories in child second language acquisiton: evidence from the acquisition of CP. Second Language Research 19, 1-41.

Haznedar, B. and Schwartz, B. 1997: Are there optional infinitives in child L2 acquisition? In Hughes, E., Hughes, M. and Greenhill, A., editors, Proceedings of the 21st Annual Boston University Conference on Language Development. Cascadilla Press, 257-68.

Herschensohn, J. 1998: Minimally raising the verb issue. In Greenhill, A., Hughes, M., Littlefield, H. and Walsh, H., editors, Proceedings from 22nd Annual Boston University Conference on Language Development. Cascadilla Press, 325-37.

Herschensohn, J. 2001: Missing inflection in L2 French: accidental infinitives and other verbal deficits. Second Language Research 17, 273-305.

Ionin, T. and Wexler, K. 2002: Why is 'is' easier than '-s'?: acquisition of tense/agreement morphology by child second language learners of English. Second Language Research 18, 95-136. 
Lakshmanan, U. 1998: Clause structure in child L2 grammars, paper presented at Generative Approaches to Second Language Acquisition, Pittsburgh.

Lardiere, D. 1998: Disassociating syntax from morphology in a divergent L2 endstate grammar. Second Language Research 14, 359-75.

2000: Mapping features to forms in second language acquisition. In Archibald, A., editor, Second Language Acquisition and Linguistic Theory. Blackwell.

MacWhinney, B. 2003: The child language data exchange system. Available at http://childes.psy.cmu.edu/ (January 2006).

Meisel, J-M. 1997: The acquisition of the syntax of negation in French and German: contrasting first and second language development. Second Language Research 13, 227-63.

Mitchell, R. and Dickson, P. 1997: Progression in foreign language learning. Centre for language in education occasional paper. No. 45, University of Southampton.

Myles, F. 2005: The emergence of morpho-syntactic structure in French L2. In Dewaele, J.M., editor, Focus on French as a foreign language: multidisciplinary approaches. Multilingual Matters.

Myles, F., Mitchell, R. and Hooper, J. 1999: Interrogative chunks in French L2: a basis for creative construction? Studies in Second Language Acquisition 21, 49-80.

Pierce, A. 1992: Language acquisition and syntactic theory: a comparative analysis of French and English child grammars. Kluwer.

Poeppel, D. and Wexler, K. 1993: The full competence hypothesis of clause structure in early German. Language 69, 1-33.

Pollock, J-Y. 1989: Verb movement, universal grammar and the structure of IP. Linguistic Inquiry 20, 365-424.

Prévost, P. 2003: Root infinitives in L2 French: a longitudinal study. In PérezLeroux, A.-T. and Roberge, Y., editors, Romance linguistics: theory and acquisition. John Benjamins, 367-84.

Prévost, P. and White, L. 2000a: Missing surface inflection or impairment in second language acquisition? Evidence from tense and agreement. Second Language Research 16, 103-33.

Prévost, P. and White, L. 2000b: Accounting for morphological variation in second language acquisition: truncation or missing inflection. In Friedemann, M.-A. and Rizzi, L., editors, The acquisition of syntax, introduction. Longman Linguistics Library.

Rizzi, L. 1994: Early null subjects and root null subjects. In Hoekstra, T. and Schwartz, B., editors, Language acquisition studies in generative grammar. Language acquisition and language disorders, volume 8. John Benjamins, 157-77.

Schwartz, B. and Sprouse, R. 1996: L2 cognitive states and the full transfer/full access model. Second Language Research 12, 40-72. 
Schütze, C. and Wexler, K. 1996: Subject case licensing and English root infinitives. In Stringfellow, A., Cahana-Amitay, D., Hughes, E. and Zukowski, A., editors, Proceedings of the 20th Annual Boston University Conference on Language Development. MIT Press, 670-81.

Smith, N. and Tsimpli, I. 1995: The mind of a savant. Blackwell.

Sprouse, R. 1998: Some notes on the relationship between inflectional morphology and parameter setting in first and second language acquisition. In Beck, M., editor, Morphology and the interfaces in second language knowledge. John Benjamins, 41-67.

Tsimpli, I. 1998: Resumptive strategies and L2A: a minimalist account, in Proceedings of the 21st Annual Boston Conference on Language Development. Volume 2, 639-56.

Vainikka, A. and Young-Scholten, M. 1994: Direct access to X' theory: evidence from Korean and Turkish adults learning German. In Hoekstra, T. and Schwartz, B.D., editors, Language acquisition studies in generative grammar. Language acquisition and language disorders, volume 8. John Benjamins, 265-316.

1996: Gradual development of L2 phrase structure. Second Language Research 12, 7-39.

Wexler, K. 1994: Optional infinitives, head movement and the economy of derivations. In Lightfoot, D. and Hornstein, N., editors, Verb movement. Cambridge University Press, 305-51.

1998: Very early parameter setting and the unique checking constraint: a new explanation of the optional infinitive stage. Lingua 106, 23-79.

White, L. 1996: Clitics in L2 French. In Clahsen, H., editor, Generative perspectives on language acquisition: empirical findings, theoretical considerations, crosslinguistic comparisons. John Benjamins, 335-69.

\section{Appendix 1 Elicitation tasks}

- Picture story: In this task, learners had to tell a story on the basis of a series of pictures. The purpose of this task is to elicit a narrative that enabled us to study sentence structure, verbal morphology, pronominal reference, gender and embedding, as well as narrative discourse features.

- Interrogative elicitation task: This task is an information gap activity in which the learners had to find out from the researcher missing information regarding the appearance, location and actions of people on a picture.

- One-to-one interview with photos: a directed conversation in which the learner had to ask questions related to a set of photos and also 
respond to questions. This task was intended to elicit all the structures investigated, with a particular focus on past tense and future verbal morphology, as well as interactive discourse features.

- Negative elicitation task: The learner had to describe a famous person by saying what they do and do not do, and the researcher guessed the mystery person. 